\title{
The Impact Of Highways On Rural Population Density
}

\author{
PETER Z. W. TSONG*
}

The purpose of this paper is to estimate the impact of highways on rural population density. A generalized population potential model was used. ${ }^{1}$ Twelve counties of Georgia and twenty-five adjacent SMSA's in Georgia, Florida, Alabama, Tennessee, North and South Carolina were selected to estimate the coefficients of the model for the census year of $1970 .^{2}$ Results show that the model is applicable to selected cities with a low population density but not to the twelve county area. ${ }^{3}$ Further research to test the limits of the model would be useful.

\section{The Model}

The model used in this analysis was developed by John Q. Stewart and William Warntz to show the relationship between the population potential and the rural population density. They tested the model with success with the data from the United States, England, Europe, and Mexico. The population potential is defined as follows:

$$
V_{i}=\sum_{j=1}^{n} \frac{P_{j}}{r_{i j}}, i=1, \ldots, m
$$

where $\mathrm{V}_{\mathrm{i}}$ is the population potential at location $\mathrm{i}, \mathrm{P}_{\mathbf{j}}$ is the population at location $\mathrm{j}, \mathrm{r}_{\mathrm{ij}}$ is the distance between location $\mathrm{i}$ and location $\mathrm{j}$, and $\mathrm{n}$ is the number of locations which contribute to the potential at location $\mathrm{i} . \mathrm{m}$ is the number of rural areas under consideration.

Stewart and Warntz showed that the following relationship between the rural population density and the population potential holds:

$$
\mathrm{D}_{\mathrm{i}}=\mathrm{kV}_{\mathrm{i}^{\prime}}^{2},
$$

where $D_{i}$ is the rural population density at location $i$ and $k$ is the constant of proportionality. This relationship can be generalized by replacing the distance $\mathrm{r}_{\mathrm{ij}}$ by a general accessibility measure such as time or cost and the equation with the following expression:

$$
\mathrm{D}_{\mathrm{i}}=\mathrm{a}+\mathrm{bV}_{\mathrm{i}}^{2} \text {, }
$$

where $\mathrm{a}$ and $\mathrm{b}$ are regression coefficients.

\footnotetext{
*The author is assistant professor in the College of Business Administration of the University of Georgia. He wishes to thank James Kau for his comments, Patti Atkinson and Robin Kidd for their assistance in gathering the data and computer programming, and Dallas Gonzales for her editorial assistance. This research is being supported by the Georgia Department of Transportation.
} 
The construct of the model is based on the assumption that the attractiveness of any location is proportional to the number of people in the large cities that can be reached through trades and visits and inversely proportional to the distance, time, or cost of travel which separates the cities from the location. The population density of the location is proportional to the attractiveness of the location. The population potential represented by equation (1) is a composite measure of attractiveness. This attractiveness is related to the rural population density by equation (3).

The generalized Stewart-Warntz model provides a convenient vehicle of estimation of the impact of highways on rural population density. Any change in the characteristics of the highway (or accessibility) changes the value of $r_{i j}$ which modifies the rural population density of the areas under study through the interaction mechanism described in equations (1) and (3). Of course, any change in the population of the large cities will also modify the population density of the rural area.

In order to avoid the problem of having to solve a system of simultaneous nonlinear equations with $\mathrm{m}$ variables and $\mathrm{m}$ equations, an assumption has been made regarding the values which may be taken by the variables. We assumed that the rural areas have relatively little effect on each other. ${ }^{4}$ Attractiveness of a rural area is largely accounted for by its accessibility to the SMSA's. Given this assumption, the values of rural population need not be included in the potential measure. We can then use the population of the SMSA's and the highway network to estimate the population density of the rural areas. The same formulation will allow us to estimate the impact of highways on the rural population density and to forecast the rural population density given the forecasted or projected values of the population of the SMSA's and the proposed changes of the highways.

\section{Data}

Estimation of coefficients a and $b$ in the model requires three types of data: the size of the population at the SMSA's and the rural areas, the size of the rural land area, and a measure of accessibility. The first two are available from the Census of Population and Housing reports, but the latter requires a substantial amount of effort in data collection. In our tests, we used cities and major population center of the counties with low population density as representation of the rural areas..$^{5}$ We used both distance and travel time as a measure of accessibility.

A formula was developed to estimate the time needed to travel from location $i$ to location $j$ allowing variations in speed limit, the number of interchanges or cross roads along the path of travel, and the number of cities and towns along the way. Assuming no congestion, the number of lanes was not included as a variable. It is a reasonable assumption for rural areas where congestion is rare. The formula is given as follows:

$$
\mathrm{t}_{\mathrm{ij}}=\sum_{\mathrm{k}=1}^{\mathrm{sij}} \frac{\mathrm{D}_{\mathrm{ij}}^{\mathrm{hk}}}{\mathrm{S}_{\mathrm{ij}}^{\mathrm{hk}}}+\mathrm{cI}_{\mathrm{ij}}+\mathrm{dC}_{\mathrm{ij}}+\sum_{\mathrm{k}=1}^{\mathrm{l}_{\mathrm{ij}}} \frac{\mathrm{D}_{\mathrm{ij}}^{\mathrm{tk}}}{\mathrm{S}_{\mathrm{ij}}^{\mathrm{tk}}}
$$


where
$\mathrm{D}_{\mathrm{ij}}^{\mathrm{hk}}=$
Length of the $\mathrm{k}^{\text {th }}$ segment of the highway within the span of $i$ and $j$.
$\mathrm{S}_{\mathrm{ij}}^{\mathrm{hk}}=$
Speed limit on the $\mathrm{k}^{\text {th }}$ segment of the highway within the span of $i$ and $j$.
$\mathrm{D}_{\mathrm{ij}}^{\mathrm{tk}}=$
Equivalent diameter of the $\mathrm{k}^{\text {th }}$ town or city within the span of $i$ and $j$.
$\mathrm{S}_{\mathrm{ij}}^{\mathrm{tk}}=$
Speed limit in the $\mathrm{k}^{\text {th }}$ town or city within the span of $\mathrm{i}$ and $\mathrm{j}$.
$\mathrm{I}_{\mathrm{ij}}=\quad$ Number of interchanges between $\mathrm{i}$ and $\mathrm{j}$.
$\mathrm{C}_{\mathrm{ij}}=\quad$ Number of cross roads between $\mathrm{i}$ and $\mathrm{j}$.
$\mathrm{c}=\quad$ Average marginal time needed to pass through an interchange.
$\mathrm{d}=\quad$ Average marginal time needed to pass a cross road. speed limits other than towns or cities within the span of $\mathbf{i}$ and $\mathbf{j}$.
$\mathrm{s}_{\mathrm{ij}}=\quad$ The number of segments with different
$\mathrm{l}_{\mathrm{ij}}=\quad$ The number of towns or cities between the span of $\mathbf{i}$ and $\mathbf{j}$.

The speed limit on the limited access highway was assumed to be 70 miles per hour. It was assumed to be 60 on the state and local highways. An arbitrary driving time was added when an interchange or cross road was encountered. An equivalent diameter for each town was calculated and then used as the distance of travel through the town at a speed of 30 miles per hour.

\section{Estimation of Coefficents}

The model was first tested using the distance matrix taken from the 1973 Georgia State Highway Map and the population of the corresponding cities taken from the population census of $1970 .{ }^{\circ}$ Thirteen cities with a population density of 2,000 persons or less per square mile were used to approximate the rural areas for the test of the model. The results were surprising. Not only was the StewartWarntz relationship found to be significant at .01 level but also the $R^{2}$ was as high as .70. They are shown in Table 1.

The positive results of the preliminary tests led us to more ambitious undertaking. Seventeen counties in Georgia, the target area of the Georgia Transportation Planning Land-Use Modeling project, were selected to give the model a more rigorous test. ${ }^{7}$ Within each county, a major population center was picked to be 
the test area. Among the 17 counties, only 12 have a population center with a population density of 2,000 persons or less per square mile. These 12 counties were used to estimate the coefficients of the model. Furthermore, a fictitious highway was created to test the sensitivity of the model toward the location of the highways. However, the results were negative regardless of whether distance or time was used as the accessibility measure. The Stewart-Warntz relationship was not even significant at 0.01 level, the $R^{2}$ 's were low, and the $b$ coefficients had the wrong sign. They are shown in Table 2 . The sensitivity test was not carried out because of the failure to find a significant relationship.

The model is not applicable to our test area. But why was it significant in the 13 city case tested earlier? We cannot find any significant differences in the pattern of growth in population between the 13 cities and the population center of the 12 counties. However, we had difficulty in getting the land area data for the population center of the counties while we did not have such problems with the cities. ${ }^{8}$ We speculate that the land area of the city is a more accurate reflection of the area of settlement than the land area of the population center of the counties where the settlement area is more loosely defined. This could be the reason why the model worked in the 13 case but not in the 12 county case. Also there is a possibility of specification bias, i.e., we have not included all the relevant variables in the model.

\section{TABLE 1}

COEFFICIENTS OF THE STEWART-WARNTZ MODEL

13 cities with population density

of 2,000 persons or less per square mile

to 22 other cities $^{1,2}$

\begin{tabular}{ccc}
\hline \multicolumn{2}{c}{$\begin{array}{c}\text { Interaction Among } \\
\text { 13 cities Excluded }\end{array}$} & \multicolumn{2}{c}{$\begin{array}{c}\text { Interaction Among } \\
13 \text { cities Included }\end{array}$} \\
Accessibility & $=$ Distance & Accessibility = Distance \\
\hline a & 466.59692 & 144.25781 \\
$\mathrm{~b}$ & $0.05316^{*}$ & $0.05134^{*}$ \\
& $(0.01068)$ & $(0.01037)$ \\
$\mathrm{t}$ & 4.97856 & 4.95039 \\
$\mathrm{R}^{2}$ & $0.6926^{*}$ & $0.6902^{*}$ \\
$\mathrm{~F}$ & 24.78861 & 24.5063 \\
\hline
\end{tabular}

*Significant at $1 \%$ level

113 cities are Bainbridge, Brunswick, Carrollton, Cartersville, Cedartown, Dalton, Dublin, Gainesville, LaGrange and Mountrie in Georgia; and Columbia, South Carolina; Jacksonville, Florida; and Nashville, Tennessee. 22 cities are Albany, Americus, Athens, Atlanta, Augusta, Columbus, Cordele, Fitzgerald, Macon, Milledgeville, Rome, Savannah, Valdosta and Waycross in Georgia; Asheville, North Carolina; Birmingham, Alabama; Charleston, South Caroliná; Chattanooga, Tennessee; Greenville, South Carolina; Montgomery, Alabama; Raleigh, North Carolina; and Tallahassee, Florida.

2Population density was measured in number of persons per square mile, and the $\mathrm{V}$ value measured in thousand persons per mile. 


\section{TABLE 2 \\ COEFFICIENTS OF THE STEWART-WARNTZ MODEL \\ 12 population center of counties \\ selected with a population density \\ of 2,000 persons or less per square mile \\ to 25 SMSA's $^{1,2}$}

Interaction Among the 12

Population Centers Excluded
Interaction Among the 12 Population Centers Included

\begin{tabular}{lcccc}
\hline & $\begin{array}{c}\text { Accessibility } \\
=\text { Distance }\end{array}$ & $\begin{array}{c}\text { Accessibility } \\
=\text { Time }\end{array}$ & $\begin{array}{c}\text { Accessibility } \\
=\text { Distance }\end{array}$ & $\begin{array}{c}\text { Accessibility } \\
=\text { Time }\end{array}$ \\
\hline $\mathrm{a}$ & 2231.03687 & 2776.14453 & 2883.84717 & 2318.54150 \\
$\mathrm{~b}$ & -0.3697 & -0.05677 & -0.05273 & -0.03769 \\
& $(0.02820)$ & $(0.03098)$ & $(0.03724)$ & $(0.02860)$ \\
$\mathrm{t}$ & -1.31097 & -1.83290 & -1.41581 & -1.31811 \\
$\mathrm{R}^{2}$ & 0.1467 & 0.2515 & 0.1670 & 0.1480 \\
$\mathrm{~F}$ & 1.7186 & 3.3595 & 2.0045 & 1.7374 \\
\hline
\end{tabular}

112 population centers are Elberton, Greensboro, Lawrenceville, Gainesville, Commerce, Comer, Madison, Covington, Crawford, Conyers, Monroe and Winder. 25 SMSA's are Albany, Atlanta, Augusta, Columbus, Macon, Savannah in Georgia; Asheville, North Carolina; Birmingham, Alabama; Charleston, South Carolina; Charlotte, North Carolina; Chattanooga, Tennessee; Columbia, South Carolina; Durham, North Carolina; Gadsden, Alabama; Greensboro-Winston-Salem-High Point, North Carolina; Greenville, South Carolina; Huntsville, Alabama; Jacksonville, Florida; Knoxville, Tennessee; Mobile, Alabama; Montgomery, Alabama; Pensacola, Florida; Raleigh, North Carolina; Tallasasee, Florida; Tuscaloosa, Alabama.

2 Population density was measured in number of persons per square mile, and the $\mathrm{V}$ value measured in thousand persons per mile.

\section{Conclusion}

Our findings show that the Stewart-Warntz model is not universally applicable to all areas. It has a much greater chance of being applicable if population density of the test area can be accurately measured and additional variables are introduced into the model. Further research on the limits and extension of the model would be useful.

\section{FOOTNOTES}

1Stewart, John W. and William Warntz, "Physics of Population Distribution," Journal of Regional Science, Volume 1, 1958, pp. 99-123.

2See Table 2 for names of the counties.

3 See Table 1 for names of the cities.

${ }^{4}$ This assumption was born out in our tests. There were no significant differences in the results whether the interaction among the rural areas was included or not.

${ }^{5}$ There are large areas in counties of Georgia that are not inhabited which renders the measure of county population density somewhat difficult to interpret. We have used the county population density in our tests with negative results.

6Only those cities which appear on both the 1973 and 1960 Georgia State Highway Map are included in the study.

'The Georgia Transportation Planning Land-Use Modeling Project is a project undertaken by the faculty of the College of Business of the University of Georgia to study the impact of alternative highway locations on population, employment, housing, and land for the Georgia Department of Transportation. The 
seventeen counties designated as target area are: Banks, Barrow, Clarke, Elbert, Franklin, Greene, Gwinnett, Hall, Hart, Jackson, Madison, Morgan, Newton, Oconee, Oglethorpe, Rockdale, and Walton.

8 We used the planimeter to measure the area of the population center of a number of counties which are not available from the census or from the local government publications or by telephone calls to the local government agencies.

\section{REFERENCES}

Anderson, Theodore R., "Potential Models and the Spatial Distribution of Population," Papers and Proceedings of the Regional Science Association, Volume 2, 1956, pp. 175-182.

Carrothers, Gerald A., "A Historical Review of the Gravity and Potential Concepts of Human Interaction," Journal of the American Institute of Planners, Spring 1956, pp. 94-102. 